\title{
SISTEM PENDAFTARAN BIMBINGAN BELAJAR MENGGUNAKAN METODE PROFILE MATCHING
}

\author{
Evi Dwi Wahyuni ${ }^{1}$, Nur Tahyudin ${ }^{2}$, Maskur $^{3}$ \\ 1,2,3 Universitas Muhammadiyah Malang \\ Jalan Raya Tlogomas 246 Malang, 65144 \\ evi.d.wahyuni@gmail.com
}

\begin{abstract}
Abstrak - Salah satu bentuk pendidikan yang dapat kita peroleh adalah bimbingan belajar. Dalam melakukan bimbingan belajar dibutuhkan proses pertemuan antara pengajar dengan pelajar. System pendaftaran bimbingan belajar menggunakan metode profil matching adalah system yang dapat menjadi media penghubung untuk pelajar dengan pengajar. Profile matching adalah sebuah metode pada system pengambilan keputusan yang menggunakan variable perbandingan data berupa kriteria-kriteria yang dimiliki antara suatu pihak dengan pihak lain. Sistem ini digunakan untuk memberikan rekomendasi pengajar kepada pelajar dengan menggunakan perbandingan data berupa kriteria - kriteria, antara lain alamat asal, alamat dimalang, hobi, riwayat pendidikan dan pengalaman. Nilai Gap yang diperoleh dari data kriteria yang dihitung pada Core Factor dan Secondary Factor selanjutnya akan dilakukan perhihungan $\mathbf{N}$ sebagai nilai total dari aspek penilaian. Dengan variable perbandingan data pada setiap aspek maka system pemesanan bimbingan belajar dapat memberikan rekomendasi pengajar kepada pelajar yang memliki tingkat kecocokan data berdasarkan perhitungan yang telah dilakukan.
\end{abstract}

Keywords - Bimbingan Belajar, Profile Matching, Gap, Core Factor, Secondary Factor

Abstract - One form of education that we can get is learning guidance. In conducting learning guidance required process of meeting between teachers and students. Learning guidance enrollment system using profile matching method is a system that can be a media for students with teachers. Profile matching is a method of decision-making system that uses variable data comparison in the form of criteria owned between a part. This system is used to provide teacher recommendations to learners by using a comparison of data in the form of criteria, among others, origin address, address in Malang, hobbies, education history and experience. The Gap value obtained from the criteria data calculated on the Core Factor and Secondary Factor will then be performed $N$ as the total value of the assessment aspect. With variable data comparison on every aspect of the ordering system guidance of learning can provide recommendations to teachers to learners who possess the level of matching data based on the calculations that have been done.

Keywords -- Bimbingan Belajar, Profile Matching, Gap, Core Factor, Secondari Factor

\section{PENDAHULUAN}

Pendidikan adalah suatu kegiatan yang pasti diperoleh setiap orang sebagai bentuk pembelajaran. Pada umumnya, pendidikan pertama kali diperoleh setiap orang berasal dari orang tua. Pendidikan berperan penting dalam membentuk karakter, dengan adanya pendidikan akan memberikan berbagai pengalaman yang bermanfaat untuk mendampingi proses tumbuh dan berkembang dalam kehidupan.

Pendidikan yang diperoleh setiap orang pada dasarnya berasal dari lembaga formal yaitu sekolah. Secara garis besar jenjang pendidikan yang ditempuh bermula dari sekolah dasar hingga pada tahap strata. Dengan bentuk pendidikan tersebut tentunya membuat para pengenyam pendidikan untuk membekali kemampuannya agar dapat bersaing dalam proses yang dilalui. Ada banyak cara untuk mendampingi pendidikan formal guna memperoleh pendidikan tambahan dengan tujuan mengulang kembali ataupun mempersiapkan kemampuan agar dapat membekali kompetensi setiap individu dengan tujuan akhir adalah hasil yang diperoleh dapat maksimal. Salah satu cara yang dapat dilakukan untuk mewujudkan hal tersebut adalah dengan mengenyam pendidikan secara non-formal, yaitu pendidikan berbentuk seperti les ataupun kursus.

Dewasa ini banyak banyak sekali bentuk pendidikan nonformal dengan berbagai disiplin ilmu yang berbeda-beda seperti les dan kursus. Les dan kursus merupakan suatu lembaga pendidikan non-formal yang pada dasarnya disediakan untuk memberikan kompetensi 
tambahan berdasarkan disiplin ilmu tertentu yang telah disediakan. Lembaga tersebut biasahnya menyediakan pendidikan dengan disiplin ilmu seperti pendidikan bahasa asing, matematika, ilmu komputer dan masih banyak lagi. Hal ini menunjukan bahwa pentingnya lembaga non-formal untuk menunjang kompetensi pada setiap individu.

Tempat les dan kursus pada umumnya memiliki metode ataupun alur yang sama, yaitu dengan melakukan pendaftaran les secara langsung pada lembaga penyedia tersebut dengan datang ketempatnya, kemudian di lanjutkan dengan pendidikan sesuai pendaftaran yang telah dilakukan. Pelaksanaan les umumnya dilakukan pada tempat yang telah disediakan oleh lembaga tersebut sehingga mewajibkan peserta les untuk datang guna mengikuti rangkaian pembelajaran. Selain itu ada juga bentuk pendidikan les yang dilakukan pada tempat peserta les dengan cara pendidik atau guru les datang secara langsung pada rumah peserta ataupun tempat yang telah disepakati sebelumnya pada saat pendaftaran.

Pada alur proses pendidikan yang disediakan oleh lembaga les ataupun kursus umunya masih secara manual dengan berbagai keterbatasan, dimana para pendaftar dibatasi dengan proses pendaftaran secara langsung pada kantor lembaga tersebut. kasus lain yang menjadi permasalahan adalah peserta les tidak dapat memilih pengajar atau guru les sesuai keinginan. Hal ini tentunya memberikan keterbatasan pada peserta les sehingga dibutuhkannya suatu sistem yang dapat memberikan kemudahan-kemudahan dalam proses pendaftaran hingga pembelajaran dalam melakukan les atau kursus.

Sistem pemesanan bimbingan belajar merupakan sebuah sistem berbasis web yang dirancang dengan tujuan untuk mengatasi keterbatasan peserta les sesuai masalah yang telah dibahas sebelumnya. Sistem ini diharapkan dapat membatu dengan mempermudah peserta les dalam segi pendaftaran dan pemilihan pengajar atau guru les serta mampu memberikan rekomendasi sesuai dengan kriteria yang telah disediakan. dalam membangun sistem pemesanan bimbingan belajar tentunya membutuhkan suatu metode yang dapat melakukan pengambilan keputusan berdasarkan permintaan peserta dengan kriteria yang dimiliki oleh pengajar. Sistem ini memiliki perbedaan dengan sistem serupa yang telah ada, dimana pada sistem-sistem bimbingan belajar lainnya berfokus pada kerjasama dengan lembaga bimbinhgan belajar yang telah ada, sedangkan pada system yang dibuat secara independen sehingga siapa saja dapat berperan sebagai pengajar ataupun pelajar. Hal lain yang ada pada sistem serupa adalah terbatasnya jumlah pelajaran yang diusung serta ditentukan oleh system, sedangkan pada system yang dibuat pengajar dapat memberikan materi pelajaran baru yang menjadi keahliannya sehingga ketersediaan materi yang diusung tidak terbatas pada sistem melainkan terbatas pada spesifikasi pengajar. Sedangkan dalam segi pembayaran, sistem dirancang menggunakan model pembayaran berdasarkan jam yang digunakan selama proses bimbingan berlangsung.
Metode yang yang dapat digunakan untuk membangun sistem pemesanan bimbingan belajar adalah metode Profile Matching. Profil Matching adalah suatu metode sistem pengambilan keputusan yang digunakan untuk menyeleksi serta mencocokan antara suatu variable inputan dengan variable pada sistem yang telah disediakan sihingga diperoleh hasil yang paling mendekati dari variable inputan [1].

\section{METODE PENELITIAN}

Profil Matching adalah suatu metode sistem pengambilan keputusan yang digunakan untuk menyeleksi serta mencocokan antara suatu variable inputan dengan variable pada sistem yang telah disediakan sihingga diperoleh hasil yang paling mendekati dari variable inputan [1].

Penerapan metode Profile Matching dalam pembuatan sistem pendaftaran bimbingan belajar secara garis besar akan dilakukan perbandingan antara kompetensi yang dimiliki ataupun yang diinginkan pelajar ke dalam kompetensi yang dimiliki pengajar sehingga dapat diketahui perbedaan kompetensinya(disebut juga gap), semakin kecil gap yang dihasilkan maka bobot nilainya semakin besar yang berarti memiliki peluang lebih besar untuk kandidat sebagai pengajar les[1]. Rumus gap sebagai pembeda antara profil pelajar dengan pengajar dapat ditunjukan pada rumus dibawah ini:

$$
\text { Gap = Profil Pengajar }- \text { Profil Pelajar }
$$

Adapun sistem program yang dibuat adalah sistem menggunakan profil matching yang berfungsi untuk melakukan proses matching antara profil pelajar dengan pengajar sehingga akan mempermudah proses dengan dengan tingkat kecocokan yang disesuaikan dengan kompetensinya.

Pada system pemesanan bimbingan belajar yang dibangun, peneliti menyusun data kriteria sebagai acuan yang digunakan untuk melakukan perhitungan guna mencocokan data yang dimiliki oleh pengajar dan pelajar. Pada implementasinya ditetapkan kriteria-kiteria yang dimiliki oleh pengajar dan pelajar, berikut kriteria tersebut:

Data alamat asal berupa:

a. Kota asal, variable kriteria untuk membandingkan alamat berupa kota asal yang dimiliki.

b. Kecamatan asal, variable kriteria untuk membandingkan alamat berupa kecamatan asal yang dimiliki.

c. Desa asal, variable kriteria untuk membandingkan alamat berupa desa asal yang dimiliki.

Data alamat di kota malang berupa:

a. Kecamatan di kota malang, variable kriteria untuk membandingkan alamat berupa kecamatan tempat tinggal.

b. Desa di kota malang, variable kriteria untuk membandingkan alamat berupa desa tempat tinggal saait ini di kota malang. 
Data riwayat Pendidikan berupa:

a. TK, sebagai variable riwayat Pendidikan yang digunakan untuk menetukan riwayat berupa tempat Pendidikan Taman kanak-kanak yang pernah dilalui.

b. SD, sebagai variable riwayat Pendidikan yang digunakan untuk menetukan riwayat berupa tempat Pendidikan Sekolah Dasar yang pernah dilalui.

c. SMP, sebagai variable riwayat Pendidikan yang digunakan untuk menetukan riwayat berupa tempat Pendidikan Sekolah Menengah Pertama yang pernah dilalui.

d.SMA, sebagai variable riwayat Pendidikan yang digunakan untuk menetukan riwayat berupa tempat Pendidikan Sekolah Menengah Atas yang pernah dilalui.

e. PT, sebagai variable riwayat Pendidikan yang digunakan untuk menetukan riwayat berupa tempat Perguruan Tinggi yang pernah dilalui.

Data kriteria hobi digunakan untuk mencocokan kedekatan antara pelajar dan pengajar melalui hobi yang dimiliki. Dan yang terakhir adalah kriteria Keahlian yang diguanakan untuk menentukan keahlian yang ingin dipelajari oleh pelajar yang juga harus dimiliki oleh pengajar.

Data kriteria diatas yang digunakan untuk menentukan pencocokan. Setelah menentukan kriteria selanjutnya yang dilakukan adalah menentukan Gap. Implementasi menunjukan diperolehnya gap pada masing-masing pelajar, setiap profil pelajar diberi bobot nilai dengan patokan table bobot nilai gap.

TABEL I

BOBOT NILAI GAP

\begin{tabular}{|c|c|c|c|}
\hline No. & $\begin{array}{c}\text { Selisih } \\
\text { (Gap) }\end{array}$ & $\begin{array}{c}\text { Nilai } \\
\text { Bobot }\end{array}$ & Keterangan \\
\hline 1 & 0 & 0 & Tidak ada gap \\
\hline 2 & 1 & 1 & Kompetensi individu +1 level \\
\hline 3 & 2 & 2 & Kompetensi individu +2 level \\
\hline 4 & 3 & 3 & Kompetensi individu +3 level \\
\hline 5 & 4 & 4 & Kompetensi individu +4 level \\
\hline
\end{tabular}

Setelah menentukan bobot nilai gap maka selanjutnya dikelompokan menjadi dua kelompok yaitu kelompok core factor dan secondary factor. Perhitungan core factor dapat ditunjukan dengan rumus:

$$
N C F=\frac{\sum N C}{\sum I C}
$$

Keterangan:

NFC : Nilai rata-rata core factor
NC : Jumlah total nilai core factor

IC : jumlah item core factor

Perhitungan secondary factor ditunjukan dengan rumus :

$$
N S F=\frac{\sum N S}{\sum I S}
$$

Keterangan:

$$
\begin{array}{ll}
\text { NSF } & \text { : Nilai rata-rata secondary factor } \\
\text { NS } & \text { : Jumlah total nilai secondary factor } \\
\text { IS } & \text { : Jumlah item secondary factor }
\end{array}
$$

Berdasarkan hasil perhitungan setiap kriteria diatas, selanjutnya adalah perhitungan nilai total, berikut rumusnya:

$$
(60 \% \times N C F)+(40 \% \times N S F)=N
$$

Keterangan:

$$
\begin{array}{ll}
\mathrm{N} & \text { : Nilai total aspek penilaian } \\
(\mathrm{x}) \% & \text { : nilai persen yang diinputkan }
\end{array}
$$

Hasil akhir yang diperoleh pada proses Profile Matching adalah rangking dari dari kandidat yang diajukan. Setelah setiap kandidat mendapat hasil akhir, maka bisa ditentukan peringkat atau ranking dari kandidat berdasarkan pada semakin besarnya nilai hasil akhir sehingga semakin besar pula kecocokannya.

\section{ANALISA DAN DESAIN SISTEM}

Hasil dari penelitian ini adalah suatu bentuk system yang dapat memberikan keputusan dalam melakukan rekomendasi pengajar kepada pelajar yang ingin melakukan bimbingan. system ini merupakan system yang berbasis web dengan menerapkan metode profile matching. berikut hasil yang diperoleh pada penelitian ini:

\subsection{Use Case}

Usecase diagram merupakan pemodelan strukturan yang menggambarkan secara garis besar dari system beserta fiturfitur yang dimiliki.

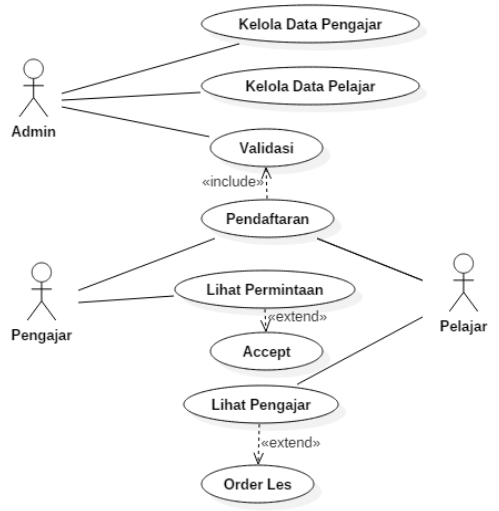

Gbr. 1. Use Case Diagram 
Gbr. 1 menunjukkan use case diagram sistem pemesanan bimbingan belajar, dimana terdapat 3 aktor yaitu admin, pengajar dan pengguna. Admin memiliki 2 fitur dalam sistem yaitu kelola data dan validasi, pengajar memiliki 2 fitur yaitu pendaftaran dan lihat permintaan yang didalamnya terdapat fitur accept, yang terakhir adalah pengguna yang memiliki 3 fitur yaitu mendaftar, lihat pengajar dan order les.

\subsection{Class Diagram}

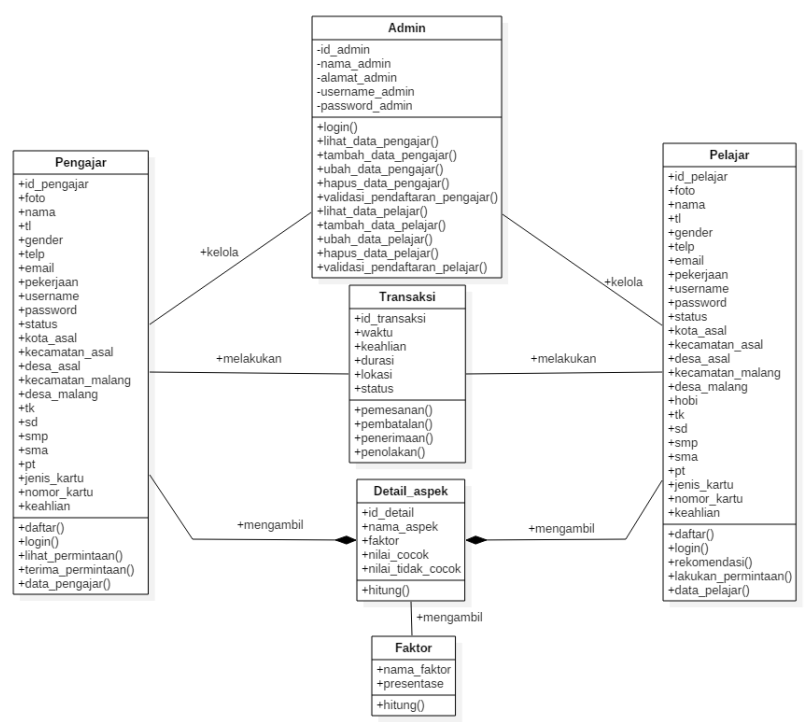

Gbr. 2 Class Diagram

Class diagram pada Gbr. 2 menunjukan seluruh entitas, variable dan method yang digunakan dalam membangun system pemesanan bimbingan belajar menggunakan metode profile matching. Dimana total keseluruhan terdapat 6 entitas yang masing - masing memiliki variable dan method. Setiap entitas pada class digram memiliki relasi masing masing dengan kondisi yang disesuaikan kebutuhan system.

\subsection{Desain Arsitektur Sistem}
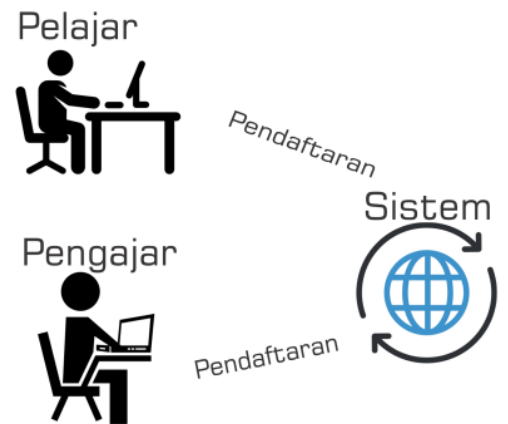

Validas
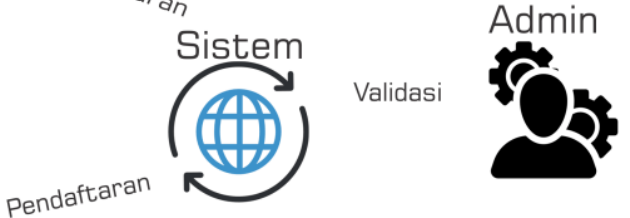

Gbr. 3 Arsitektur Menu Pendaftaran
Gbr. 3 menunjukkan arsitektur menu pendaftaran yang memiliki tiga aktor yaitu pelajar, pengajar, dan admin. Pelajar dan pengajar dapat melakukan pendaftaran melalui system, sedangkan admin bertugas untuk melakukan validasi.

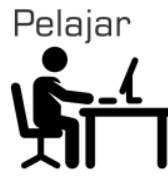

$$
\begin{aligned}
& \text { Meminta Bimbingan } \\
& \text { Belajar }
\end{aligned}
$$
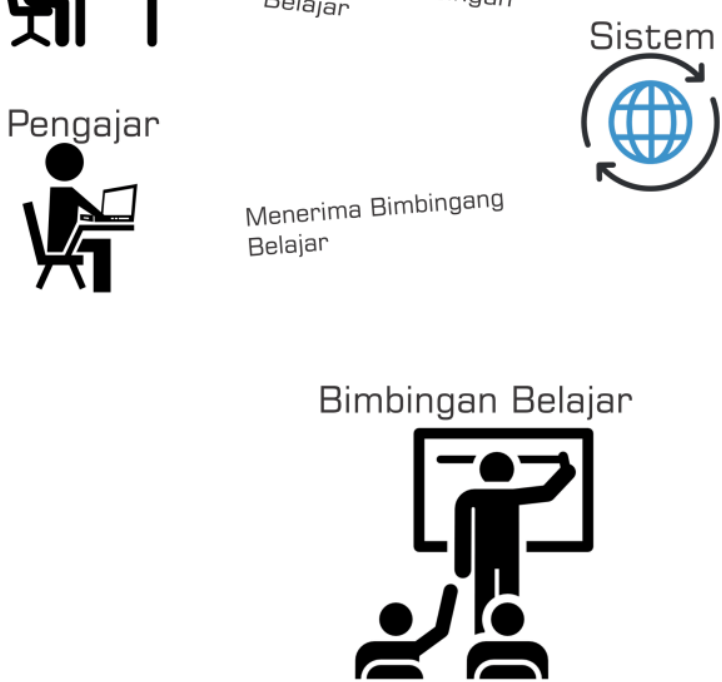

Gbr. 4 Arsitektur permintaan, penerimaan dan proses bimbingan belajar

Perancangan sistem dimulai dengan 2 aktor yang mendaftar terlebih dahulu, yaitu aktor pertama mendaftar sebagai pengajar atau guru les sedangkan aktor kedua mendaftar sebagai pengguna. Setelah kedua aktor melakukan pendaftaran maka data akan masuk ke sistem yang dikelola oleh admin yang kemudian divalidasi agar pendaftar dapat masuk dan menggunakan sistem sebagai pengajar atau pengguna.

Setelah data tervalidasi, pengajar maupun pengguna dapat menggunakan fitur yang telah disediakan oleh sistem. Pengajar menunggu adanya pengguna yang melakukan order les sedangkan pengguna dapat melihat profil pengajar ataupun melakukan ordes les kepada pengajar yang di inginkan maupun pengajar hasil dari rekomendasi sistem. Ketika pengguna telah melakukan order, maka pengajar dapat melakukan tindakan berupa validasi guna menerima permintaan les ataupun tidak. Setelah roses selesai hal selanjutnya adalah berlangsungnya proses mengajar yang dilakukan oleh pengajar kepada pelaku order secara langsung sesuai kesepakatan yang ada.

\section{PEMBAHASAN}

Pada bab ini akan dibahas bagaimana implementasi dan pengujian pada system pemesanan bimbingan belajar menggunakan metode profile matching. 


\subsection{Implementasi}

Pada sub bab implementasi akan dijelaskan mengenai fitur berupa menu pada setiap user yang dimiliki oleh system serta fungsi dari masing masing fitur pada user tersebut. Interface yang ditunjukkan pada jurnal ini adalah interface yang dalam pembuatan kodenya menggunakan metode Profile Matching.

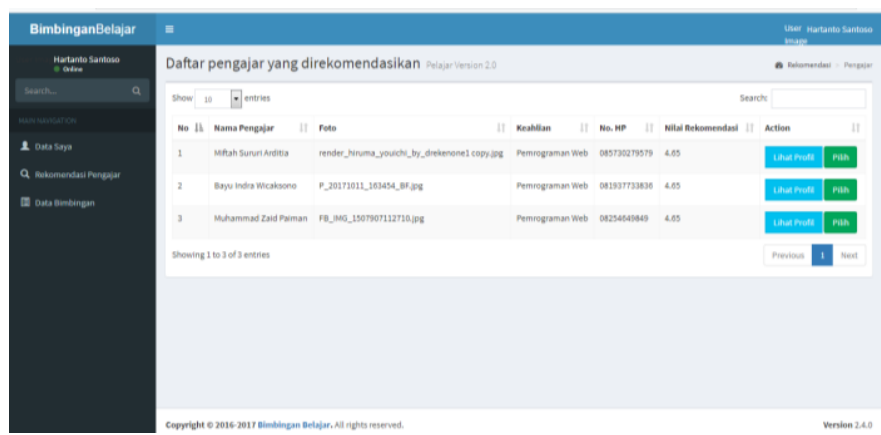

Gbr. 5 Interface Rekomendasi Pengajar

Pada halaman ini dilakukan pengujian pencocokan data yang telah di inputkan saat melakukan pendaftaran. Data menunjukan bahwa pelajar memperoleh rekomendasi pengajar dari system berdasarkan perhitungan yang dilakukan menggunakan metode profile matching terhadap semua data yang dimiliki oleh pelajar dan pengajar pada sistem. Data sample sebagai pengujian dengan nilai batas bawah yang digunakan adalah keahlian yang tidak sesuai sedangkan nilai batas atas adalah keahlian yang direkomendasikan tidak sesuai.

\subsection{Pengujian}

Dalam pengujian menggunakan metode Black Box Testing yang telah dilakukan oleh peneliti dapat diketahui bahwa dalam system pemesanan bimbingan belajar menggunakan metode profile matching masih memiliki kekurangan diantaranya tidak ada Batasan nilai bawah guna penilaian serta tidak adanya penyeleksian data secara tepat. Hal lain yang dapat dilihat dari hasil pengujian pada system adalah tingkat keberhasilan rekomendasi pengajar kepada pelajar menggunakan metode profile matching yag dapat mencocokan variabel berupa data yang dimiliki oleh pelajar dan pengajar. System juga berhasil dalam melakukan pemesanan bimbingan belajar yang mana seorang pelajar dapat melakukan pemesana kepada pelajar menggunakan system pemesanan bimbingan belajar menggunakan metode profile matching.

\section{PENUTUP}

Berdasarkan hasil penelitian yang sudah dilakukan dengan menggunakan metode profile matching untuk memberikan rekomendasi pengajar kepada pelajar pada system yang dibangun dapat disimpulkan bahwa :

1. Sistem yang dibangun merupakan system pendaftaran bimbingan belajar berbasis web yang dapat mempertemukan penguna sebagai pelajar pengajar.
Dalam implementasinya system dapat memberikan keputusan berupa rekomendasi pengajar kepada pelajar.

2. Pengolahan data pengajar dan pelajar yang digunakan sebagai variable pencocokan nilai pada metode profile matching sebagai metode system pengambilan keputusan yang dibangun sangatlah efektif dimana dengan adanya metode tersebut seorang pengajar dapat lebih mudah menemukan pengajar yang sesuai dengan kebutuhan dan kondisi individualnya.

3. Pengujian menggunakan metode Black Box Testing dengan Teknik Boundary Value Analusis/Limit Testing menunjukan bahwa hasil metode profile matching pada system pemesanan bimbingan belajar dapat memberikan rekomendasi yang sesuai kepada pelajar dalam menemukan pengajar serta menunjukan keberhasilan system dalam melakukan pendaftaran, login, dan melakukan proses pemesanan bimbingan belajar.

\section{UCAPAN TERIMA KASIH}

Ucapan terima kasih kami sampaikan kepada seluruh pihak yang telah membantu terselesaikannya laporan penelitian ini, masukan dan kritikan yang membangun akan sangat membantu dalam perbaikan di masa mendatang.

\section{REFERENSI}

[1] Angkasa Seradi. 2016. Penerapan Metode Profilr Matching untuk Menentukan Kelayakan Pemberian Kredit pada PNPM Mandiri Kota Banjarmasing. Banjarmasing. Jurnal Teknologi Informasi. Vol . XI Nomor 31

[2] Bassil Youssef, 2012, Simulation Model for the Waterfall Software Development Life Cycle, International Journal of Engineering \& Technology (iJET), ISSN: 2049-3444, Vol. 2, No. 5, 2012.

[3] Kusrini., Mukhsin, A. 2006. Sistem Pendukung Keputusan Evaluasi Kinerja Karyawan untuk Promosi Jabatan. Prosiding Kopwil IV Volume II No.3 Kopertis Wilayah IV Jawa Barat dan Banten.

[4] Kusrini. 2007. Konsep dan Aplikasi Sistem Pendukung Keputusan. Yogyakarta: C.V Andi Offset

[5] Zhu Haojin, Du Suguo, Li Muyuan, and Gao Zhaoyu. 2013. Fairness Aware and Privacy-Preserving Friend Matching Protocol in Mobile Social Networks. Digital Object Identifier. 10.1109/TETC.2013.2279541.

[6] Gautam Bhaskar, Jain Vivek, Sourabh Jain, and B. Annappa. 2016. Profile Matching of Online Social Network with Aadhaar Unique Identification Number. IEEE. DOI 10.1109/CCEM.2016.3.

[7] Rahmadiansyah Dudi, Irwan Dedy. 2012. Implementasi Metode Model View Controller Menggunakan Framework Code Igniter dalam Pengembangan Aplikasi Manajemen Depo Petikemas pada Unit Usaha Belawan Logistics Center. Seminar Nasional Teknologi Informasi dan Komunikasi (SNASTIKOM 2012). ISBN 978-602-19837-0-6. 
[8] Mustaqbal M. Sidi, Fajri Firdaus Roeri, Rahmadi Hendra. 2015. Pengujian AplikasI Menggunakan Black Box Testing Boundary Value Analysis (Studi Kasus : Aplikasi Prediksi Kelulusan SNMPTN). Jurnal Ilmiah Teknologi Informasi Terapan Volume I, No 3. ISSN : 2407 3911. 